\title{
OPEN Assumptions about fence permeability influence density estimates for brown hyaenas across South Africa
}

\begin{abstract}
Kathryn S. Williams ${ }^{1,2,9}$, Samual T. Williams ${ }^{1,2,3,4,9 \bowtie}$, Rebecca J. Welch ${ }^{5}$, Courtney J. Marneweck ${ }^{5}$, Gareth K. H. Mann ${ }^{7,8}$, Ross T. Pitman, ${ }^{7,8}$, Gareth Whittington-Jones ${ }^{7}$, Guy A. Balme ${ }^{7,8}$, Daniel M. Parker ${ }^{5,6}$ \& Russell A. Hill,1,2,3

Wildlife population density estimates provide information on the number of individuals in an area and influence conservation management decisions. Thus, accuracy is vital. A dominant feature in many landscapes globally is fencing, yet the implications of fence permeability on density estimation using spatial capture-recapture modelling are seldom considered. We used camera trap data from 15 fenced reserves across South Africa to examine the density of brown hyaenas (Parahyaena brunnea). We estimated density and modelled its relationship with a suite of covariates when fenced reserve boundaries were assumed to be permeable or impermeable to hyaena movements. The best performing models were those that included only the influence of study site on both hyaena density and detection probability, regardless of assumptions of fence permeability. When fences were considered impermeable, densities ranged from 2.55 to 15.06 animals per $100 \mathrm{~km}^{2}$, but when fences were considered permeable, density estimates were on average 9.52 times lower (from 0.17 to 1.59 animals per $100 \mathrm{~km}^{2}$ ). Fence permeability should therefore be an essential consideration when estimating density, especially since density results can considerably influence wildlife management decisions. In the absence of strong evidence to the contrary, future studies in fenced areas should assume some degree of permeability in order to avoid overestimating population density.
\end{abstract}

Natural barriers such as bodies of water and mountain ranges influence movement patterns and gene flow in wildlife populations ${ }^{1-3}$. Man-made physical barriers such as roads and fences similarly impact wildlife ${ }^{4-7}$. With the human population undergoing exponential growth and a continuing demand for ecotourism, enclosing wildlife in fenced areas is widespread in southern Africa ${ }^{8,9}$. Fences demarcate boundaries, reduce human-wildlife conflict, protect resources, and prevent disease transmission; yet they also disrupt the natural movement patterns of animals, which can cause ecosystem imbalances such as reducing genetic influx and causing over-exploitation of resources ${ }^{8,10}$. As a result, fencing for conservation is highly controversial ${ }^{8,11}$.

In many parts of the world, wildlife is confined to fenced areas, and this is especially true in South Africa where it is a legal requirement to fence an area containing dangerous game species ${ }^{8,12}$. Although fences are often successful at confining cattle and large herbivores, fences are semi-permeable for many mammals including some large predators ${ }^{13-15}$. Holes under fences are created by erosion and by digging species ${ }^{16}$, and when a fence line is breached, species detect and exploit holes quickly ${ }^{17}$. To maintain the integrity of a fence, continuous upkeep is required which is costly (approximately US $\$ 32,000$ per annum to maintain $100 \mathrm{~km}$ of fencing in South Africa) ${ }^{16}$.

\footnotetext{
${ }^{1}$ Department of Anthropology, Durham University, Dawson Building, South Road, Durham DH1 3LE, UK. ${ }^{2}$ Primate and Predator Project, PO Box 522, Louis Trichardt 0920, South Africa. ${ }^{3}$ Department of Zoology, University of Venda, Thohoyandou 0950, South Africa. ${ }^{4}$ Institute for Globally Distributed Open Research and Education (IGDORE), Johannesburg, South Africa. ${ }^{5}$ School of Biology and Environmental Sciences, University of Mpumalanga, Nelspruit 1200, South Africa. ${ }^{6}$ Wildlife and Reserve Management Research Group, Department of Zoology and Entomology, Rhodes University, PO Box 94, Grahamstown 6140, South Africa. ${ }^{7}$ Panthera, 8 W 40th Street 18th Floor, New York, NY 10018, USA. ${ }^{8}$ Institute for Communities and Wildlife in Africa, University of Cape Town, Private Bag X3, Rondebosch 7701, South Africa. ${ }^{9}$ These authors contributed equally: Kathryn S. Williams and Samual T. Williams. ${ }^{\square}$ email: samual.t.williams@gmail.com
} 
Maintenance of the majority of fences is underfunded in Africa, leading to a high occurrence of boundaries that are semi-permeable for species such as mammalian carnivores ${ }^{10}$.

In reserves where fences, including predator proof fences, are not maintained to the highest standard, brown hyaenas (Parahyaena brunnea) transverse boundaries by digging new holes and opportunistically expanding pre-existing holes ${ }^{18}$. Although brown hyaenas can survive, and often succeed, outside of protected areas, the highest population densities of brown hyaenas have been reported in small fenced reserves that are thought to be impermeable to the movement of brown hyaenas ${ }^{19-21}$. It is speculated that these brown hyaena population densities resulted from a lack of emigration, small reserve size, an abundance of large sympatric predators (carrion providers), and high levels of prey availability ${ }^{19,21}$. The influence of these factors on hyaena population density (the number of individuals per unit area), however, has not been tested.

Spatial capture-recapture (SCR) is a common method utilised to estimate densities from camera trap images ${ }^{22}$. The state variable in SCR is a spatial point process where each point represents an individual's activity centre, and the state-space incorporates these regions of activity centres ${ }^{23}$. The hypothesis being that animals with activity centres outside of this state-space region have little chance of being captured ${ }^{23}$. One is free to specify the state-space and therefore estimates will be biased if this area is so small that some captured animals have activity centres outside of this region. In enclosed areas, some researchers restrict the state-space to fence lines when estimating population densities of large carnivores using SCR modelling ${ }^{19,21,24,25}$. In open areas or fenced areas where cross-boundary movement is probable, a larger state-space buffer is employed in SCR modelling to encompass home ranges and activity centres that span beyond the study area ${ }^{26,27}$. How one deals with individuals that do not necessarily reside within a reserve but do traverse, and are detected, within it (i.e. the definition of the state-space), therefore has strong implications for the density estimates produced. The accuracy of density estimates is paramount as they are often central to conservation management decisions, yet there is a paucity of research on how assumptions regarding the permeability of fenced reserve boundaries (i.e. the defined statespace) affects density estimates, especially for large carnivores.

Due to their small population size and high levels of intentional and accidental persecution, brown hyaenas are listed as Near Threatened both globally ${ }^{28}$ and regionally in South Africa ${ }^{29}$. Their current resident range is restricted to six countries including South Africa, which is thought to support approximately $20 \%$ of the total remaining population ${ }^{29}$. Furthermore, research into the distribution, population size, and trends of brown hyaenas at a national scale has been identified as a top priority for brown hyaena conservation ${ }^{28,29}$, requiring reliable density estimates over a large area. In this study, we estimate the population density of brown hyaenas in 15 fenced reserves in South Africa, making two contrasting assumptions about the permeability of the reserve boundary fences to the movement of brown hyaenas at each site: 1) reserve boundaries are impermeable (with the state-space clipped to the reserve boundary fence line), and 2) reserve boundaries are permeable (with a larger, unclipped state-space). We consider the repercussions of varying state-space in SCR modelling and the implications for conservation management when assessing fenced areas. In addition, we investigate which factors drive brown hyaena density at fenced sites and compare the results when fences are considered impermeable and permeable.

\section{Results}

At 15 survey sites across South Africa (Fig. 1, Table 1) we collected 2690 camera trapping capture events of brown hyaenas (Table S1). We discarded 298 (11.08\%) brown hyaena captures because image quality was insufficient to allow identification of individuals (Table S1). The majority of discarded captures had only one photograph $(\mathrm{n}=289)$; therefore, the hyaena was only visible from one side, making identification more difficult. A total of 362 identifiable brown hyaenas were captured on 2392 occasions (Table S1).

The top population density models relating to both assumptions of fence permeability included only the site covariate on both $g 0$ (detection probability when the distance between the activity centre of an animal and the camera trap is zero) and on density (Table 2, Table S2). Density estimates derived from the top model ranged from 2.55 to 15.06 animals per $100 \mathrm{~km}^{2}$ at each site when fences were considered to be impermeable, and from 0.17 to 1.59 animals per $100 \mathrm{~km}^{2}$ when fences were considered to be permeable to hyaena movement (Fig. 2, Table S3).

When fences were assumed to be permeable, hyaena density estimates were on average 9.5 times lower than when fences were assumed to be impermeable to hyaena movement. Furthermore, we found an inverse relationship between reserve size and the ratio of brown hyaena density estimates modelled using different assumptions about fence permeability (Fig. 3, Table 3). In contrast, population size estimates were 1.6 times greater for models that assumed fence permeability (see Table S4). The general patterns of activity centre location were relatively similar for both model permeable and impermeable formulations at most study sites (Fig. S1). Estimates in smaller reserves were more sensitive to assumptions regarding the permeability of reserve boundaries to brown hyaena movement.

\section{Discussion}

Our study represents the largest and widest-ranging collection of density estimates to date for brown hyaenas. Our density estimates for each site varied substantially depending on whether fences were considered to be permeable or impermeable to the movement of brown hyaenas. Hyaena population densities were approximately ten times greater among impermeable estimates than permeable estimates due to the state-space difference associated with this assumption.

The population density of brown hyaenas has been estimated at only a handful of sites that are fully enclosed by fencing ${ }^{19,21,32,33}$, despite fences encompassing a large proportion of protected and non-protected land throughout the species range $e^{8,9,34}$. Overall, our estimates fit within the ranges of most previous studies ${ }^{20,21,35,36}$. Our estimates for permeable fenced areas (0.17-1.59 animals per $\left.100 \mathrm{~km}^{2}\right)$ were slightly lower than, but comparable 


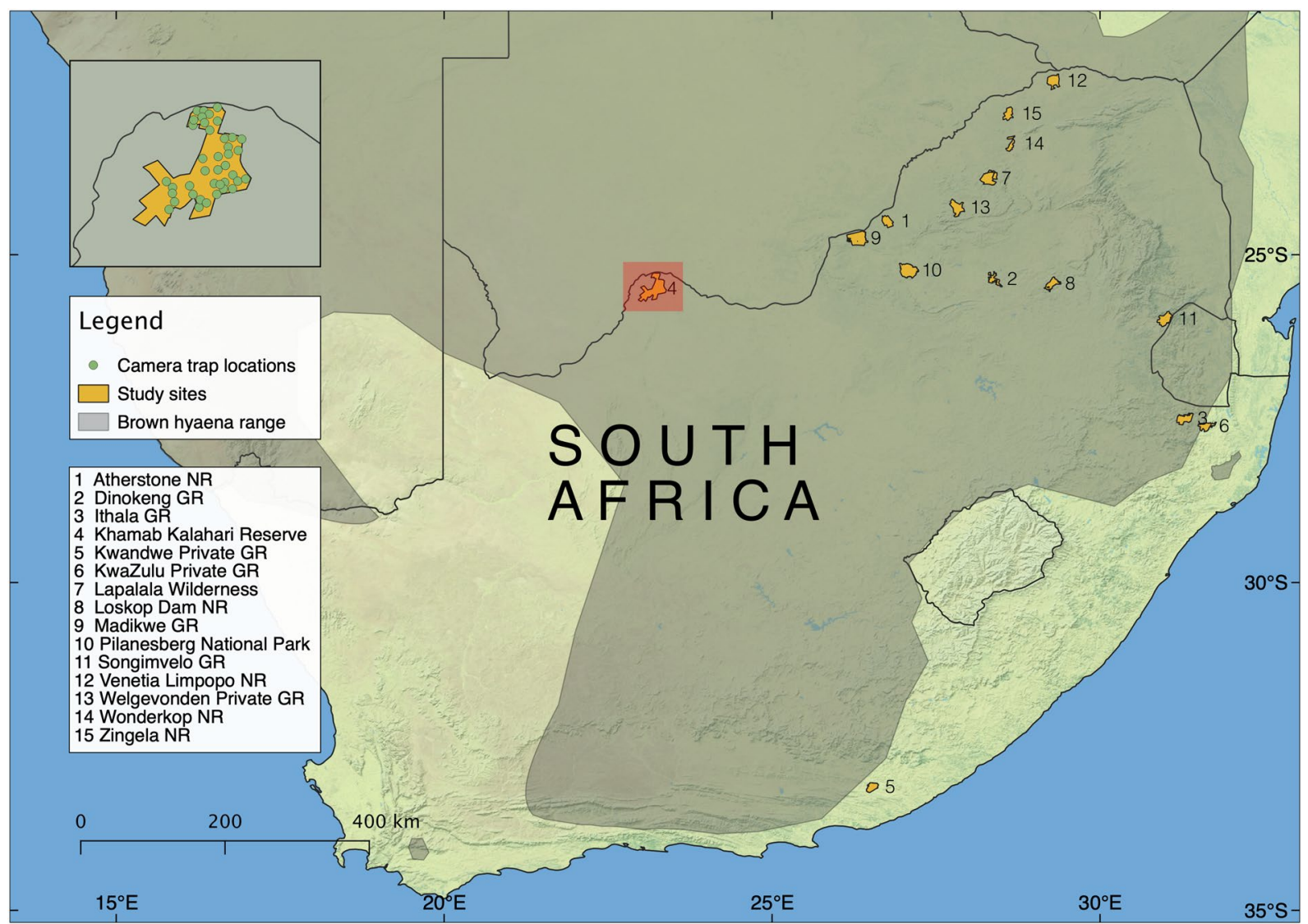

Figure 1. Map showing the locations of the survey sites where brown hyaena population densities were estimated. Inset map shows an example layout of a camera trap array at Khamab Kalahari Reserve. In the legend NR refers to Nature Reserve, and GR refers to Game Reserve. Created using QGIS $3.10 .10^{30}$, using hyaena range data from ${ }^{28}$ and base map data from ${ }^{31}$.

\begin{tabular}{|c|c|c|c|c|c|}
\hline Survey site & Reserve size $\left(\mathbf{k m}^{2}\right)$ & $\begin{array}{l}\text { Minimum convex polygon of camera trap } \\
\text { area }\left(\mathbf{k m}^{2}\right)\end{array}$ & Survey period & Camera stations & Survey effort (trap nights) \\
\hline Atherstone Nature Reserve & 240 & 180 & Oct 2016-Dec 2016 & 36 & 1797 \\
\hline Dinokeng Game Reserve & 185 & 173 & Jul 2016-Aug 2016 & 36 & 1586 \\
\hline Ithala Game Reserve & 296 & 236 & July 2016-Sep 2016 & 30 & 1315 \\
\hline Khamab Kalahari Reserve & 955 & 570 & Aug 2016-Oct 2016 & 37 & 1744 \\
\hline Kwandwe Private Game Reserve & 183 & 135 & Mar 2017-Apr 2017 & 40 & 1860 \\
\hline KwaZulu Private Game Reserve & 185 & 135 & Nov 2015-Dec 2015 & 34 & 2645 \\
\hline Lapalala Wilderness & 360 & 331 & Oct 2016-Dec 2016 & 39 & 1932 \\
\hline Loskop Dam Nature Reserve & 232 & 170 & Oct 2016-Dec 2016 & 34 & 1774 \\
\hline Madikwe Game Reserve & 600 & 306 & Nov 2016-Dec 2016 & 36 & 1472 \\
\hline Pilanesberg National Park & 550 & 247 & Mar 2016-Apr 2016 & 40 & 1785 \\
\hline Songimvelo Game Reserve & 490 & 112 & Mar 2016-Apr 2016 & 27 & 1127 \\
\hline Venetia Limpopo Nature Reserve & 316 & 237 & Jul 2016-Aug 2016 & 39 & 1934 \\
\hline Welgevonden Private Game Reserve & 375 & 203 & Apr 2016-May 2016 & 40 & 1292 \\
\hline Wonderkop Nature Reserve & 160 & 150 & Jan 2015-Mar 2015 & 37 & 1579 \\
\hline Zingela Nature Reserve & 219 & 177 & May 2016-Jun 2016 & 39 & 1690 \\
\hline
\end{tabular}

Table 1. Camera trap surveys in South Africa. Camera area is the minimum convex polygon area covered by camera trap stations. Survey effort is the total number of trap nights each camera survey was active. Camera area is the minimum convex polygon of the camera trap array. 


\begin{tabular}{|c|c|c|c|c|c|c|}
\hline Fence permeability & Model & $\begin{array}{l}\text { Number of } \\
\text { parameters }\end{array}$ & logLik & AICc & $\Delta \mathrm{AICc}$ & AICcwt \\
\hline \multirow[t]{17}{*}{ Impermeable } & g0 session & 17 & $-13,583.25258$ & $27,202.264$ & 0 & 1 \\
\hline & D 1 g0 ReserveSize & 5 & $-13,726.6259$ & $27,463.418$ & 261.154 & 0 \\
\hline & g0 PreyRAI & 4 & $-13,728.84766$ & $27,465.806$ & 263.542 & 0 \\
\hline & g0 HumanRAI & 4 & $-13,731.93908$ & $27,471.989$ & 269.725 & 0 \\
\hline & D 1 g0 SpHyRAI & 5 & $-13,780.73571$ & $27,571.638$ & 369.374 & 0 \\
\hline & $\mathrm{D} \sim 1 \mathrm{~g} 0 \sim$ LeopardRAI & 5 & $-13,789.21782$ & $27,588.602$ & 386.338 & 0 \\
\hline & $\begin{array}{l}\text { D 1 g0 Human- } \\
\text { Density }\end{array}$ & 5 & $-13,790.37303$ & $27,590.913$ & 388.649 & 0 \\
\hline & $\mathrm{D} \sim 1 \mathrm{~g} 0 \sim 1$ & 4 & $-13,811.65901$ & $27,631.429$ & 429.165 & 0 \\
\hline & $\mathrm{D} \sim 1 \mathrm{~g} 0 \sim \mathrm{b}$ & 5 & $-13,810.74387$ & $27,631.654$ & 429.39 & 0 \\
\hline & D $\sim$ session g0 $\sim$ session & 32 & $-13,619.62238$ & $27,309.587$ & 0 & 1 \\
\hline & $\begin{array}{l}\text { D HumanRAI g0 ses- } \\
\text { sion }\end{array}$ & 19 & $-13,656.18928$ & $27,352.575$ & 42.988 & 0 \\
\hline & $\mathrm{D} \sim 1 \mathrm{~g} 0 \sim$ session & 18 & $-13,662.96435$ & $27,363.9$ & 54.313 & 0 \\
\hline & $\begin{array}{l}\mathrm{D} \sim \text { SpHyRAI g0 ses- } \\
\text { sion }\end{array}$ & 19 & $-13,662.189$ & $27,364.575$ & 54.988 & 0 \\
\hline & $\begin{array}{l}\mathrm{D} \sim \text { PreyRAI g0 } \sim \text { ses- } \\
\text { sion }\end{array}$ & 19 & $-13,662.4187$ & $27,365.034$ & 55.447 & 0 \\
\hline & $\begin{array}{l}\text { D LeopardRAI } \\
\text { g0 session }\end{array}$ & 19 & $-13,662.96355$ & $27,366.124$ & 56.537 & 0 \\
\hline & $\begin{array}{l}\text { D HumanDensity } \\
\text { g0 session }\end{array}$ & 19 & $-13,663.26425$ & $27,366.725$ & 57.138 & 0 \\
\hline & $\begin{array}{l}\text { D ReserveSize } \\
\text { g0 session }\end{array}$ & 19 & $-13,667.47856$ & $27,375.154$ & 65.567 & 0 \\
\hline \multirow[t]{17}{*}{ Permeable } & D 1 g0 session & 18 & $-13,758.6739$ & $27,555.319$ & 0 & 0.9571 \\
\hline & D 1 g0 SpHyRAI & 5 & $-13,775.68221$ & $27,561.531$ & 6.212 & 0.0429 \\
\hline & $\mathrm{D} \sim 1$ g0 HumanRAI & 5 & $-13,784.58262$ & $27,579.332$ & 24.013 & 0 \\
\hline & D 1 g0 LeopardRAI & 5 & $-13,786.04496$ & $27,582.257$ & 26.938 & 0 \\
\hline & $\mathrm{D} \sim 1$ g0 ReserveSize & 5 & $-13,788.84003$ & $27,588.547$ & 33.228 & 0 \\
\hline & $\begin{array}{l}\text { D 1 g0 Human- } \\
\text { Density }\end{array}$ & 5 & $-13,799.30979$ & $27,608.786$ & 53.467 & 0 \\
\hline & $\mathrm{D} \sim 1 \mathrm{~g} 0 \sim \mathrm{b}$ & 5 & $-13,803.15885$ & $27,616.484$ & 61.165 & 0 \\
\hline & $\mathrm{D} \sim 1 \mathrm{~g} 0 \sim 1$ & 4 & $-13,807.76959$ & $27,623.65$ & 68.331 & 0 \\
\hline & $\mathrm{D} \sim 1 \mathrm{~g} 0 \sim$ PreyRAI & 5 & $-13,807.89884$ & $27,625.964$ & 70.645 & 0 \\
\hline & D session g0 session & 32 & $-13,700.353$ & $27,471.049$ & 0.00 & 1 \\
\hline & $\begin{array}{l}\mathrm{D} \sim \text { PreyRAI g0 ses- } \\
\text { sion }\end{array}$ & 19 & $-13,755.963$ & $27,552.123$ & 81.07 & 0 \\
\hline & $\begin{array}{l}\mathrm{D} \sim \text { SpHyRAI g0 ses- } \\
\text { sion }\end{array}$ & 19 & $-13,756.577$ & $27,553.35$ & 82.30 & 0 \\
\hline & $\begin{array}{l}\text { D HumanRAI g0 ses- } \\
\text { sion }\end{array}$ & 19 & $-13,756.795$ & $27,553.786$ & 82.74 & 0 \\
\hline & $\mathrm{D} \sim 1 \mathrm{~g} 0 \sim$ session & 20 & $-13,758.674$ & $27,555.319$ & 84.27 & 0 \\
\hline & $\begin{array}{l}\text { D LeopardRAI } \\
\text { g0 session }\end{array}$ & 19 & $-13,758.376$ & $27,556.948$ & 85.90 & 0 \\
\hline & $\begin{array}{l}\text { D HumanDensity } \\
\text { g0 session }\end{array}$ & 19 & $-13,759.67107$ & $27,559.539$ & 88.49 & 0 \\
\hline & $\begin{array}{l}\text { D ReserveSize } \\
\text { g0 session }\end{array}$ & 19 & $-13,763.359$ & $27,566.915$ & 95.87 & 0 \\
\hline
\end{tabular}

Table 2. Comparison of models of $g 0$ and density fitted to camera trap data of brown hyaena captures across South Africa. Parameters include: D (density estimate) and $g 0$ (baseline detection). Covariates include: b (learned response; $g 0$ only); session (site), LeopardRAI (relative abundance index (RAI) of leopards), SpHyRAI (RAI of spotted hyaenas), HumanRAI (RAI of humans), HumanDensity (population density of humans) PreyRAI (RAI of prey species), ReserveSize (size of reserve). All models utilised the hazard rate detection function. Models shown in bold are the top models within each subset.

with, the few available previous brown hyaena density estimates in permeable fenced reserves (approximately 3 animals per $100 \mathrm{~km}^{232,33}$ ). When fences were assumed to be impermeable, our brown hyaena density estimates (2.55-15.06 animals per $100 \mathrm{~km}^{2}$ ) were also comparable to the high density estimates calculated using SCR in fenced areas assumed to be impermeable to hyaena movements $\left(15^{21}\right.$ to $24.01^{19}$ brown hyaenas per $\left.100 \mathrm{~km}^{2}\right)$. 


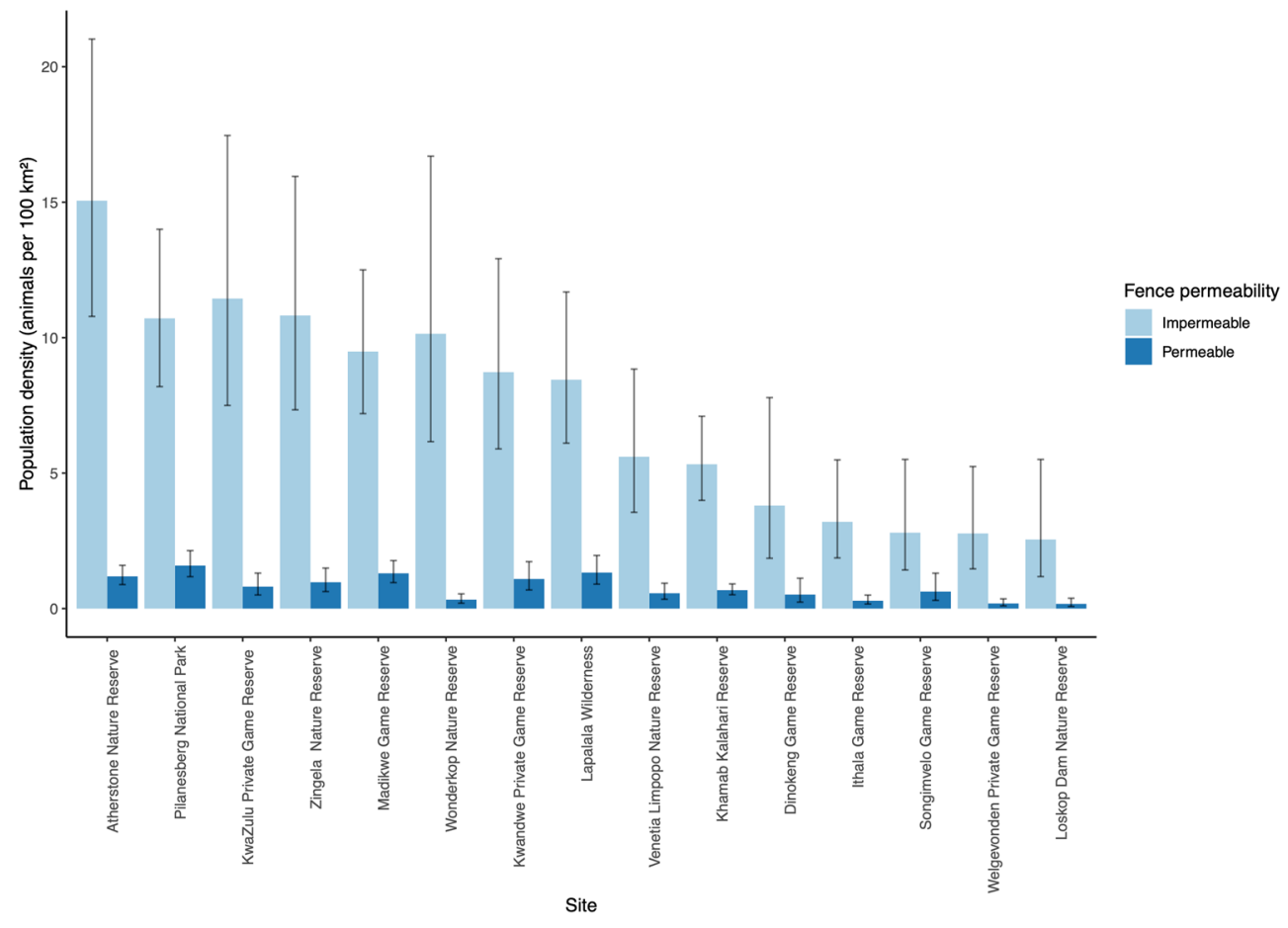

Figure 2. Population density estimates for brown hyaenas as each site assuming that fences were either permeable or impermeable to hyaena movement. Error bars show $95 \%$ confidence intervals.

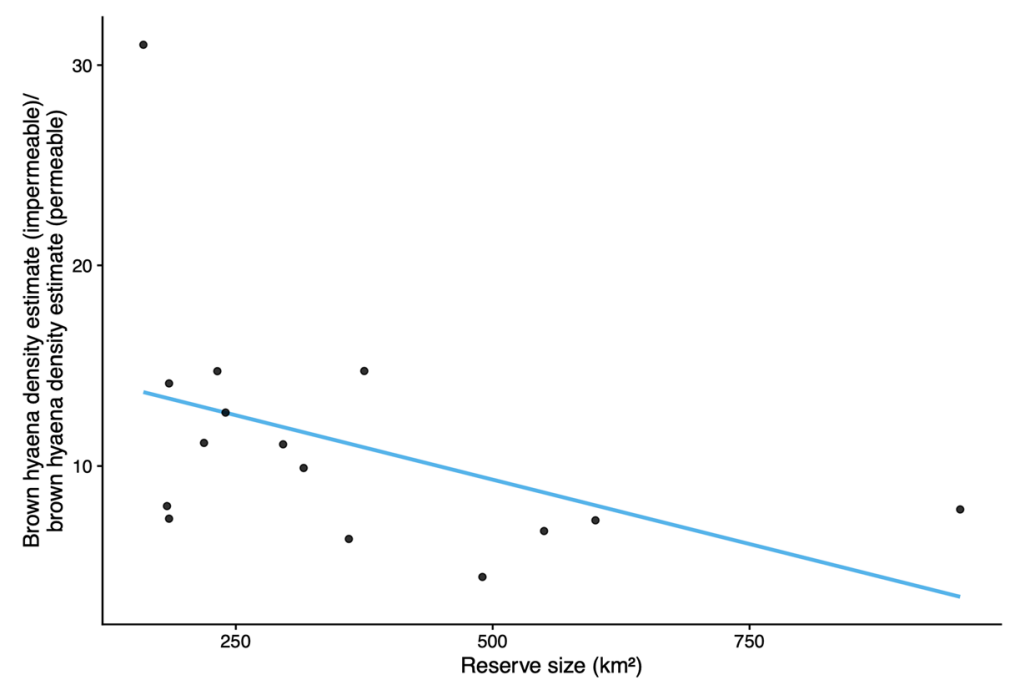

Figure 3. Relationship between reserve size and the ratio of brown hyaena population density estimates when using differing assumptions of fence permeability.

\begin{tabular}{|l|l|l|l|}
\hline Distribution & AIC & dAIC & Degrees of freedom \\
\hline Inverse Gaussian & 87.0 & 0.0 & 3 \\
\hline Gamma & 89.6 & 2.6 & 3 \\
\hline Null model & 91.9 & 4.9 & 2 \\
\hline Gaussian & 100.0 & 13.0 & 3 \\
\hline
\end{tabular}

Table 3. Comparison of fit between models of the relationship between reserve size and the ratio of brown hyaena density estimated using differing assumptions of fence permeability. 
Many studies do not restrict the state-space to fence lines and reserve boundaries, resulting in relatively low density estimates ${ }^{22,37-39}$. Less commonly the state-space is restricted to fences, often resulting in record high densities ${ }^{19,21,24}$. Our results show that the corresponding change in the state-space buffer used in SCR analysis when fences are assumed to be permeable or impermeable to animal movements results in substantially different densities, even when using the same capture histories, which may have important repercussions with regard to carnivore management objectives.

We found that the implications of truncating the state-space to the fence line are area dependant, where smaller reserves are more sensitive to assumptions regarding fence permeability than larger reserves. In larger areas, the trapping grid is likely located further away from the fence line, and thus density estimates are less sensitive to the state-space defined because the individuals exposed to sampling in these areas should be mostly those that have their activity centres within the reserve. In contrast, in smaller areas the trapping grid is likely located closer to the fence line and thus the individuals exposed to sampling in these areas are more likely to hold activity centres outside of the reserve. Consequently, assuming fences are impermeable (i.e. truncating the state-space) in a small, enclosed reserve would likely yield highly over-estimated densities. This indicates that decisions regarding fence permeability should not be taken lightly when studying less extensive reserves or more fragmented habitats, which are relatively common in countries such as South Africa that make up a large proportion of the range of brown hyaenas ${ }^{40,41}$.

In addition, we suggest a more nuanced approach to defining habitat. Brown hyaenas are likely to be able to survive outside of protected areas across much of rural southern Africa. However, large carnivore densities are likely to be higher within protected areas ${ }^{42}$. This is not reflected in the estimates of population size, which assume equal habitat quality both within and outside of protected areas, and are thus likely to produce inflated population estimates when fences are assumed to be permeable. We suggest that future studies acknowledge this reality by including a measure of habitat quality into the state space mask used in SCR analyses ${ }^{43,44}$. This will allow researchers to account for the likely permeability of reserve fences, while simultaneously modelling the probable costs to individuals ranging outside of the reserve (lower habitat suitability, greater risk of persecution, etc.).

One of the main challenges of this study was the lack of reliable data on fence permeability and the extent of movement by brown hyaenas at each survey site. Due to the size of the reserves, the number of survey sites, and financial and temporal constraints, we were unable to accurately quantify the potential for brown hyaena movement through fences, thus leading us to examine two extremes of fence permeability. The assumption of complete permeability or impermeability is unlikely to be entirely accurate in the way predators use landscapes, and in reality, the permeability of many fences will likely lie somewhere between these extremes. For example African wild dogs (Lycaon pictus) can cross the "predator-proof" fence surrounding our Pilanesberg National Park study site $^{45}$, so even predator-proof fencing often has some degree of permeability. Movement will be concentrated around holes in the fence line, thus creating spatial heterogeneity in fence permeability. Furthermore, as animals dig holes, fences are damaged or fall into disrepair, or fences are maintained, the degree of permeability will change dynamically over time, compounding the challenge of making objective and meaningful assessments of fence permeability. At present there is also no way of incorporating these data directly into available SCR models, but the development of such models would be one way to help calculate more accurate density estimates in these systems, should collection of fence quality data be possible. If fence holes are documented and remain persistent, they could be modelled using non-euclidean distance methods and integrated into SCR models (M. Efford, pers. comm.). The successful incorporation of permanent holes in density modelling will likely encourage methods to be devised that consider movement through ephemeral holes.

For both scenarios of fence permeability, the models with the most support included only the site covariate in models of both $g 0$ and hyaena population density. This suggests that site-specific factors were stronger determinants of brown hyaena abundance and detection probability than the other covariates included in the models. It was interesting that no support was found for an association between the relative abundance index (RAI) of competitor species and brown hyaena density, as variables were predictors of brown hyaena occupancy ${ }^{46}$. It is also possible that RAI lacks the precision to tease out these effects, and covariates such as absolute leopard (Panthera pardus) density may perform differently to leopard RAI, although these data are not yet available. Although RAI can be biased by ecological factors and sampling design ${ }^{47}$, numerous camera trapping studies use RAI as a proxy for covariates, especially when density estimates are unavailable $39,46,48$.

One potential caveat of the study is that camera trap spacing is a key element of SCR study design, so care should be taken to ensure that bycatch data are used appropriately. Our results could therefore be biased by estimating brown hyaena density using data that were collected using a design optimised for the estimation of leopard density, if leopards had much larger home ranges than brown hyaenas. But since brown hyaenas tend to have similar or larger home ranges than leopards ${ }^{49-51}$, we would expect the results to be comparable to a survey dedicated to brown hyaenas, and we would design the camera trap arrays in a very similar pattern for both species. Such a wide-ranging study using such a large dataset would not have been possible without using bycatch data.

\section{Conclusion}

Assumptions regarding the permeability of fencing to the movement of brown hyaenas had a great influence on population density estimates in SCR models, with density estimates being approximately ten times greater in models assuming impermeable fences than in models assuming permeable fences. We recommend that researchers consider if the density estimates are appropriate to the definition of the state-space used and fence permeability assumptions. We also suggest that further exploration of the distribution of estimated activity centres within and outside reserves could help in providing recommendations for defining the state-space because our results show that density estimates are heavily influenced by these assumptions. How these density estimates 
are influenced by sampling a continuum across both sides of the fence is an important future avenue of research to properly evaluate permeability assumptions. Of the covariates we included in the models, the site was the only one that was associated with brown hyaena density. This assessment, the first on such a broad scale, will provide useful baseline information for brown hyaena population monitoring and conservation programmes. Our results show that large carnivore population density estimates are vastly inflated when fences are assumed to be impermeable. These data may be misleading, resulting in poor management decisions. Consequently, we strongly recommend that future studies assume a degree of fence permeability unless there is compelling evidence to the contrary, ideally supported by additional sampling outside of the fenced area.

\section{Methods}

Study area. The study was conducted in 15 fenced reserves located in South Africa's Eastern Cape, Gauteng, KwaZulu-Natal, Limpopo, North West, and Mpumalanga provinces (Fig. 1). The reserves were (in alphabetical order) Atherstone Nature Reserve, Dinokeng Game Reserve, Ithala Game Reserve, Khamab Kalahari Reserve, Kwandwe Private Game Reserve, KwaZulu Private Game Reserve, Lapalala Wilderness, Loskop Dam Nature Reserve, Madikwe Game Reserve, Pilanesberg National Park, Songimvelo Game Reserve, Venetia Limpopo Nature Reserve, Welgevonden Private Game Reserve, Wonderkop Nature Reserve, and Zingela Nature Reserve. The reserves ranged from 160 to $955 \mathrm{~km}^{2}$ in size (Table 1), and ecotourism is the main land use for all sites. Kwandwe Private Game Reserve was the only site where brown hyaenas were reintroduced in the past 20 years $^{21}$. Human population density within $10 \mathrm{~km}$ of each reserve varied between provinces, ranging from a mean of 8 people per $\mathrm{km}^{2}$ in Limpopo to 214 people per $\mathrm{km}^{2}$ in Gauteng (data from ${ }^{52}$ ).

All camera trap surveys were enclosed within the fences of the reserve boundaries. Fence quality and the level of maintenance varied between sites. Despite most reserve fences being electrified $(n=11)$, communication with landowners and managers, personal observations of fence line quality, and previous research indicate brown hyaena movement through fences was thought to be theoretically possible at all sites with the exception of Kwandwe Private Game Reserve. Kwandwe's perimeter fence was checked for holes and maintained daily, and a camera trap survey on adjacent properties did not record brown hyaenas, while they are abundant within the reserve ${ }^{53}$.

Camera trap surveys. Camera trap surveys were established in each reserve to estimate the population density of leopards using SCR modelling. Camera trap stations were separated by a mean of 2.05 (SD 0.48$) \mathrm{km}$. This spacing, based on the average home range size of female leopards, ensures that all leopards in the study area have the opportunity to be photographed ${ }^{54}$. We utilised camera trap images of brown hyaenas collected by these camera traps (bycatch data) to model the population density of brown hyaenas. Analysing bycatch data is an efficient use of resources in conservation, provided species-specific methodological discrepancies are considered and accounted for ${ }^{46,55,56}$. Bycatch data on brown hyaenas from camera traps initially set up to survey leopards were used to successfully conduct occupancy analysis ${ }^{46}$. Similarities between leopards and brown hyaenas in detectability on camera traps, height, use of roads and trails, home range size, and geographical overlap make them an ideal pairing for data sharing opportunities ${ }^{46}$. This is the first study to estimate brown hyaena density using bycatch data.

Brown hyaena home range size varies between habitats ${ }^{21,32,36}$. Home range estimates collected at our survey sites were only available for Kwandwe Private Game Reserve, Madikwe Game Reserve, and Pilanesberg National Park ${ }^{21,51}$. The smallest recorded brown hyaena home range is at Kwandwe $\left(26.32 \mathrm{~km}^{2}\right)$, which relates to a maximum suggested camera spacing of $2.89 \mathrm{~km}^{21}$. Since Kwandwe is the second smallest reserve sampled and the only reserve likely to be impermeable, it is probable that brown hyaenas in Kwandwe have one of the smallest home range sizes of all survey sites. Since the spacing used in this study was smaller than the maximum suggested spacing, all brown hyaenas with home ranges overlapping camera trapping survey areas had the chance to be photographed, thus fulfilling key requirements of SCR modelling ${ }^{57}$.

Camera trap data were used to estimate brown hyaena density once at each reserve. Data collection for this analysis was completed between January 2015 and April 2017, with the majority of data collected in 2016 (Table 1). The mean size of the reserves was $356 \mathrm{~km}^{2}$, which were surveyed using an average of 36 paired camera trap stations (72 camera traps), covering a minimum convex polygon of $224 \mathrm{~km}^{2}$ for an average of 1702 trap nights. Sampling periods were between 37 and 56 days, which was sufficiently brief to avoid violating the assumption of a closed population ${ }^{23,58}$, yet long enough for individuals to be photographed on multiple occasions ${ }^{59}$.

We placed Panthera V-series digital camera traps (camera models V4, V5, and V6) in locations large carnivores were likely to frequent such as on roads or game trails. Cameras were mounted on trees or poles in opposing but slightly staggered pairs to avoid the camera flash negatively affecting the images recorded by the paired cameras. The paired setup ensured that both flanks of passing animals were photographed to aid identification. We downloaded images and maintained the cameras on a weekly or fortnightly basis.

Data analysis. Citizen scientists identified species photographed in camera trap images to a species level using the Zooniverse platform (www.zooniverse.org). To ensure confidence in identification, five independent classifications were averaged per image. Brown hyaenas were then individually identified by two experienced assessors using unique features such as leg stripes, snare wounds, and ear notches ${ }^{20}$. Both assessors verified each image at least three times to ensure accurate identification. Any images that could not be accurately identified were excluded from the analysis ${ }^{60}$. Brown hyaenas do not exhibit significant sexual dimorphism ${ }^{61}$ and it was not possible to distinguish between males and females. In situations where photographs only captured one side of the animal, we included the most commonly photographed set of singular flanks (left or right) at each survey site 
to avoid artificially inflating population estimates by counting an individual's left and right flanks as two separate individuals ${ }^{62,63}$. No images of immature individuals were collected, so this study relates to adults only.

Sampling occasions for brown hyaenas were defined as a 24-h period from 12:00 pm to 11:59 am. By incorporating the full duration of the night, we avoided the 'midnight problem' whereby an animal photographed on both sides of midnight is recorded as separate captures ${ }^{64}$. This approach is recommended for species such as the brown hyaena that is almost exclusively nocturnal ${ }^{27}$.

To estimate hyaena population density we fitted SCR models to the data within a maximum likelihood framework using the package secr v. 3.2.165 in R 3.6.066. We fitted a multi-session model to our data, in which each reserve was treated as a single session ${ }^{67}$. We fitted half-normal, hazard rate, and negative exponential detection functions to the data, and retained the function with the lowest Akaike information criterion corrected for small sample sizes (AICc) ${ }^{68}$. The best supported spatial detection function was hazard rate, and this was used in subsequent models (Table S5). The models of $g 0$ with the AICc for both impermeable and permeable fences included only the site covariate (Table 2). We therefore included site as a covariate on $g 0$ in all models of population density. We used the derived function in secr to compute estimates of $g 0$ and density for each site within each model. We modelled three parameters - population density, $g 0$, and $\sigma$ (the spatial scale parameter). We also estimated population size using the region. $N$ function in secr, and plotted activity centres from the fitted model objects using the $f x$.total function in secr, which produces a map showing the probability of each pixel in the habitat mask being the activity centre of both observed and unobserved individuals. This allowed us to visually compare the spatial distribution of activity centres between fence-permeable and impermeable models for each study site.

To investigate the relationship between brown hyaena density and a range of potential explanatory variables, we modelled the relationship between reserve size, and the RAI of prey, leopard, spotted hyaena (Crocuta crocuta), and humans (on foot) on brown hyaena population density and $g 0$. We also modelled the relationship between site and $g 0$, and we fitted a learned response model, in which the probability of detection at the home range centre was affected by previous captures. Covariates were selected based on brown hyaena occupancy ${ }^{46}$, and speculated, but previously untested, drivers of brown hyaena density ${ }^{19,21}$. We estimated human population density in the area surrounding each reserve by calculating the mean density (humans per $\mathrm{km}^{2}$ ) within a $10 \mathrm{~km}$ radius of the reserve boundaries (data from ${ }^{52}$ ). We calculated RAI as the number of captures per 100 camera-trap days ${ }^{69,70}$. Captures excluded consecutive photographs of the same species at the same location more than once in a 30 min interval ${ }^{71}$. Prey RAI included species with an average female weight of $15 \mathrm{~kg}$ or more, based on brown hyaena dietary studies showing a preference for medium and large sized prey ${ }^{72-74}$. RAI values were standardised as $\mathrm{z}$-scores ${ }^{75}$. Covariates were included separately in each model, and models were compared using $\mathrm{AIC}_{\mathrm{c}}{ }^{68}$. We retained all models with $\Delta \mathrm{AIC}_{\mathrm{c}}<2^{76}$. The final model used to estimate brown hyaena population densities included the best models on $g 0$ and density.

State space buffers were used to estimate home range centres that extend beyond the camera trapping area ${ }^{77}$. To examine the role of the permeability of fences on reserve boundaries to the movement of study animals and the resulting population density we fitted two sets of SCR models; one set in which the state space was restricted to the fence line (impermeable), and one with the state space buffer extending beyond the fence line (permeable). We used the suggest.buffer function in secr and applied the largest buffer suggested $(31 \mathrm{~km})$ to all sites in order to be conservative ${ }^{78}$. A home range centre spacing of $500 \mathrm{~m}$ was used in both sets of models. Areas of human infrastructure uninhabitable to brown hyaenas were excluded from the habitat masks. Model fitting was conducted using the Durham University High Performance Computing service. We tested the relationship between reserve size and the ratio of hyaena population densities estimated using the two assumptions of fence permeability (impermeable:permeable to hyaena movement) using a generalised linear model with an inverse gaussian distribution. This approach was the best fit to our data, which did not have a normal distribution. Data and code to reproduce the analyses are publicly available ${ }^{79}$.

Received: 20 March 2020; Accepted: 5 November 2020

Published online: 12 January 2021

\section{References}

1. Brumfield, R. T. \& Edwards, S. V. Evolution into and out of the Andes: a Bayesian analysis of historical diversification in Thamnophilus antshrikes. Evolution 61, 346-367 (2007).

2. Machado, A. P., Clément, L., Uva, V., Goudet, J. \& Roulin, A. The Rocky Mountains as a dispersal barrier between barn owl (Tyto alba) populations in North America. J. Biogeogr. 45, 1288-1300 (2018).

3. Patton, J. L., Da Silva, M. N. F. \& Malcolm, J. R. Gene genealogy and differentiation among arboreal spiny rats (Rodentia: Echimyidae) of the Amazon basin: a test of the riverine barrier hypothesis. Evolution 48, 1314-1323 (1994).

4. Trinkel, M. et al. Inbreeding and density-dependent population growth in a small, isolated lion population. Anim. Conserv. 13, 374-382 (2010).

5. Vanak, A. T., Thaker, M. \& Slotow, R. Do fences create an edge-effect on the movement patterns of a highly mobile mega-herbivore?. Biol. Conserv. 143, 2631-2637 (2010).

6. Parchizadeh, J. et al. Roads threaten Asiatic cheetahs in Iran. Curr. Biol. 28, R1141-R1142 (2018).

7. Williams, S. T., Collinson, W., Patterson-Abrolat, C., Marneweck, D. G. \& Swanepoel, L. H. Using road patrol data to identify factors associated with carnivore roadkill counts. PeerJ 7, e6650 (2019).

8. Hayward, M. W. \& Kerley, G. I. H. Fencing for conservation: restriction of evolutionary potential or a riposte to threatening processes?. Biol. Conserv. 142, 1-13 (2009)

9. Taylor, A., Lindsey, P., Davies-Mostert, H. \& Goodman, P. An assessment of the economic, social and conservation value of the wildlife ranching industry and its potential to support the green economy in South Africa. 1-163 (The Endangered Wildlife Trust, Johannesburg, South Africa, 2015).

10. Pekor, A. et al. Fencing Africa's protected areas: costs, benefits, and management issues. Biol. Conserv. 229, 67-75 (2019). 
11. Woodroffe, R., Hedges, S. \& Durant, S. M. To fence or not to fence. Science 344, 46-48 (2014).

12. Hayward, M. W. \& Somers, M. J. An introduction to fencing for conservation. In Fencing for Conservation: Restriction of Evolutionary Potential or a Riposte to Threatening Processes? (eds Somers, M. J. \& Hayward, M.) 1-6 (Springer, Berlin, 2012).

13. Cozzi, G., Broekhuis, F., McNutt, J. W. \& Schmid, B. Comparison of the effects of artificial and natural barriers on large African carnivores: implications for interspecific relationships and connectivity. J. Anim. Ecol. 82, 707-715 (2013).

14. Kesch, M. K., Bauer, D. T. \& Loveridge, A. J. Break on through to the other side: the effectiveness of game fencing to mitigate human-wildlife conflict. Afr. J. Wildl. Res. 45, 76-87 (2015).

15. Pirie, T. J., Thomas, R. L. \& Fellowes, M. D. Game fence presence and permeability influences the local movement and distribution of South African mammals. Afr. Zool. 52, 217-227 (2017).

16. Lindsey, P. A., Masterson, C. L., Beck, A. L. \& Romañach, S. Ecological, social, and financial issues related to fencing as a conservation tool in Africa. In Fencing for Conservation: Restriction of Evolutionary Potential or a Riposte to Threatening Processes? (eds Somers, M. J. \& Hayward, M.) 215-234 (Springer, Berlin, 2012).

17. Connolly, T. A., Day, T. D. \& King, C. M. Estimating the potential for reinvasion by mammalian pests through pest-exclusion fencing. Wildl. Res. 36, 410-421 (2009).

18. Kesch, K. M., Bauer, D. T. \& Loveridge, A. J. Undermining game fences: who is digging holes in Kalahari sands?. Afr. J. Ecol. 52, $144-150$ (2013).

19. Edwards, S., Noack, J., Heyns, L. \& Rodenwoldt, D. Evidence of a high-density brown hyena population within an enclosed reserve: the role of fenced systems in conservation. Mammmal Res. 64, 519-527 (2019).

20. Kent, V. T. \& Hill, R. A. The importance of farmland for the conservation of brown hyaena, Parahyaena brunnea. Oryx 47, 431-440 (2013).

21. Welch, R. J. \& Parker, D. M. Brown hyaena population explosion: rapid population growth in a small, fenced system. Wildl. Res. 43, 178-187 (2016).

22. Rogan, M. S. et al. The influence of movement on the occupancy-density relationship at small spatial scales. Ecosphere 10, e02807 (2019).

23. Efford, M. G. \& Fewster, R. M. Estimating population size by spatially explicit capture-recapture. Oikos 122, 918-928 (2013).

24. Noack, J., Heyns, L., Rodenwoldt, D. \& Edwards, S. Leopard density estimation within an enclosed reserve, Namibia using spatially explicit capture-recapture models. Animals 9, 724 (2019).

25. Balme, G. et al. Big cats at large: Density, structure, and spatio-temporal patterns of a leopard population free of anthropogenic mortality. Popul. Ecol. 61, 256-267 (2019).

26. Noss, A. J. et al. Comparison of density estimation methods for mammal populations with camera traps in the Kaa-Iya del Gran Chaco landscape. Anim. Conserv. 15, 527-535 (2012).

27. Foster, R. J. \& Harmsen, B. J. A critique of density estimation from camera-trap data. J. Wildl. Manag. 76, 224-236 (2012).

28. Wiesel, I. Parahyaena brunnea. The IUCN Red List of Threatened Species 2015: e.T10276A82344448., Available from http://dx.doi. org/https://doi.org/10.2305/IUCN.UK.2015-4.RLTS.T10276A82344448.en [Accessed 1 March 2020] (2015).

29. Yarnell, R. et al. A conservation assessment of Parahyaena brunnea. In The Red List of Mammals of South Africa, Swaziland and Lesotho (eds Child, M. F. et al.) (South African National Biodiversity Institute and Endangered Wildlife Trust, Midrand, 2016).

30. QGIS Development Team. QGIS Geographic Information System version 3.10.10. Open Source Geospatial Foundation Project (Available from http://qgis.org) (2020).

31. Natural Earth.Available from http://www.naturalearthdata.com [Accessed Feb 01 2020] (2020).

32. Thorn, M., Scott, D. M., Green, M., Bateman, P. W. \& Cameron, E. Z. Estimating brown hyaena occupancy using baited camera traps. Afr. J. Wildl. Res. 39, 1-10 (2009).

33. Yarnell, R. W. et al. The influence of large predators on the feeding ecology of two African mesocarnivores: the black-backed jackal and the brown hyaena. Afr. J. Wildl. Res. 43, 155-166 (2013).

34. Falkena, H. B. \& van Hoven, W. Bulls, bears and lions: game ranch profitability in southern Africa (The South Africa Financial Sector Forum, Midrand, 2000).

35. Thorn, M., Green, M., Bateman, P. W., Waite, S. \& Scott, D. M. Brown hyaenas on roads: estimating carnivore occupancy and abundance using spatially auto-correlated sign survey replicates. Biol. Conserv. 144, 1799-1807 (2011).

36. Wiesel, I. Predatory and foraging behaviour of brown hyenas (Parahyaena brunnea (Thunberg, 1820)) at cape fur seal (Arctocephalus pusillus pusillus Schreber, 1776) colonies PhD thesis, University of Hamburg, (2006).

37. Brassine, E. \& Parker, D. Trapping elusive cats: using intensive camera trapping to estimate the density of a rare African felid. PLoS ONE 10, e0142508 (2015).

38. Ramesh, T., Kalle, R., Rosenlund, H. \& Downs, C. T. Low leopard populations in protected areas of Maputaland: a consequence of poaching, habitat condition, abundance of prey, and a top predator. Ecol. Evol. 7, 1964-1973 (2017).

39. Miller, J. R., Pitman, R. T., Mann, G. K., Fuller, A. K. \& Balme, G. A. Lions and leopards coexist without spatial, temporal or demographic effects of interspecific competition. J. Anim. Ecol. 87, 1709-1726 (2018).

40. Trinkel, M. et al. Translocating lions into an inbred lion population in the Hluhluwe-iMfolozi Park, South Africa. Anim. Conserv. 11, 138-143 (2008).

41. Thompson, S., Avent, T. \& Doughty, L. S. Range analysis and terrain preference of adult southern white rhinoceros (Ceratotherium simum) in a South African private game reserve: insights into carrying capacity and future management. PLoS ONE 11, e0161724 (2016)

42. Balme, G. A., Slotow, R. \& Hunter, L. T. B. Edge effects and the impact of non-protected areas in carnivore conservation: leopards in the Phinda-Mkhuze Complex, South Africa. Anim. Conserv. 13, 315-323 (2010).

43. Royle, J. A., Chandler, R. B., Sun, C. C. \& Fuller, A. K. Integrating resource selection information with spatial capture-recapture. Methods Ecol. Evol. 4, 520-530 (2013).

44. Proffitt, K. M. et al. Integrating resource selection into spatial capture-recapture models for large carnivores. Ecosphere 6, 1-15 (2015).

45. Davies-Mostert, H. T. et al. Long-distance transboundary dispersal of African wild dogs among protected areas in southern Africa. Afr. J. Ecol. 50, 500-506 (2012).

46. Williams, K. S. et al. Utilizing bycatch camera-trap data for broad-scale occupancy and conservation: a case study of the brown hyaena Parahyaena brunnea. Oryx, 1-11, (2020).

47. Sollmann, R., Mohamed, A., Samejima, H. \& Wilting, A. Risky business or simple solution - Relative abundance indices from camera-trapping. Biol. Conserv. 159, 405-412 (2013).

48. Palmer, M. S., Swanson, A., Kosmala, M., Arnold, T. \& Packer, C. Evaluating relative abundance indices for terrestrial herbivores from large-scale camera trap surveys. Afr. J. Ecol. 56, 791-803 (2018).

49. Swanepoel, L. H. et al. A conservation assessment of Panthera pardus. In The Red List of South Africa, Swaziland and Lesotho (eds Child, M. F. et al.) (South African National Biodiversity Institute and Endangered Wildlife Trust, Midrand, 2016).

50. Williams, K. S. Human-brown hyaena relationships and the role of mountainous environments as refuges in a postcolonial landscape PhD thesis, Durham University, (2017).

51. Richmond-Coggan, L. Comparative abundance and ranging behaviour of brown hyaena (Parahyaena brunnea) inside and outside protected areas in South Africa PhD thesis, Nottingham Trent University, (2014). 
52. WorldPop.South Africa $100 \mathrm{~m}$ population, Available from https://www.worldpop.org/doi/https://doi.org/10.5258/SOTON/WP002 46. [Accessed 30 May 2020] (2013).

53. Welch, R. J. Population estimates and spatial ecology of brown hyaenas in Kwandwe Private Game Reserve MSc thesis, Rhodes University, (2014).

54. Karanth, K. U., Nichols, J. D. \& Samba-Kumar, N. Ch.7: Estimating tiger abundance from camera trap data: field surveys and analytical issues. In Camera traps in animal ecology: methods and analyses (eds O'Connell, A. F. et al.) 97-118 (Springer, Berlin, 2011).

55. Edwards, S. et al. Making the most of by-catch data: assessing the feasibility of utilising non-target camera trap data for occupancy modelling of a large felid. Afr. J. Ecol. 56, 885-894 (2018).

56. Mazzamuto, M. V., Valvo, M. L. \& Anile, S. The value of by-catch data: how species-specific surveys can serve non-target species. Eur. J. Wildl. Res. 65, 68 (2019).

57. Sun, C. C., Fuller, A. K. \& Royle, J. A. Trap configuration and spacing influences parameter estimates in spatial capture-recapture models. PLoS ONE 10, e0141634 (2014).

58. Otis, D. L., Burnham, K. P., White, G. C. \& Anderson, D. R. Statistical inference from capture data on closed animal populations. Wildlife Monogr. 62, 3-135 (1978).

59. Kays, R. W. \& Slauson, K. M. Ch.5: Remote cameras. In Noninvasive survey methods for carnivores (eds Long, R. A. et al.) 110-140 (Island Press, Washington, 2008).

60. Williams, S. T., Williams, K. S., Lewis, B. P. \& Hill, R. A. Population dynamics and threats to an apex predator outside of protected areas: Implications for carnivore management. Roy. Soc. Open. Sci. 4, 1-10 (2017).

61. Mills, M. G. L. The comparative behavioural ecology of the brown hyaena Hyaena brunnea and the spotted hyaena Crocuta crocuta in the southern Kalahari. Koedoe 27, 237-247 (1984).

62. Kent, V. T. The status and conservation potential of carnivores in semi-arid rangelands, Botswana the Ghanzi farmlands: a case study $\mathrm{PhD}$ thesis, Durham University, (2011).

63. Satter, C. B. et al. Long-term monitoring of ocelot densities in Belize. J. Wildl. Manag. 83, 283-294 (2019).

64. Jordan, M. J., Barrett, R. H. \& Purcell, K. L. Camera trapping estimates of density and survival of fishers Martes pennanti. Wildl. Biol. 17, 266-276 (2011).

65. Efford, M. G. secr: Spatially explicit capture-recapture models. R package version 3.2.1. (Available from http://cran.r-project.org/ package $=$ secr) (2019).

66. R Development Core Team. R: A language and environment for statistical computing. Version 3.6.0 (Available from https://www.Rproject.org/.) (2019).

67. Bahaa-ed-din, L. et al. Effects of human land-use on Africa’s only forest-dependent felid: The African golden cat Caracal aurata. Biol. Conserv. 199, 1-9 (2016).

68. Loock, D. J., Williams, S. T., Emslie, K. W., Matthews, W. S. \& Swanepoel, L. H. High carnivore population density highlights the conservation value of industrialised sites. Sci. Rep-UK 8, 16575 (2018).

69. Carter, N. H., Shrestha, B. K., Karki, J. B., Pradhan, N. M. B. \& Liu, J. G. Coexistence between wildlife and humans at fine spatial scales. Proc. Natl. Acad. Sci. U.S.A. 109, 15360-15365 (2012).

70. Treves, A., Mwima, P., Plumptre, A. J. \& Isoke, S. Camera-trapping forest-woodland wildlife of western Uganda reveals how gregariousness biases estimates of relative abundance and distribution. Biol. Conserv. 143, 521-528 (2010).

71. O'Brien, T. G., Kinnaird, M. F. \& Wibisono, H. T. Crouching tigers, hidden prey: Sumatran tiger and prey populations in a tropical forest landscape. Anim. Conserv. 6, 131-139 (2003).

72. Williams, K. S., Williams, S. T., Fitzgerald, L. E., Sheppard, E. C. \& Hill, R. A. Brown hyaena and leopard diets on private land in the Soutpansberg Mountains, South Africa. Afr. J. Ecol. 56, 1021-1027 (2018).

73. Maddock, A. H. Analysis of brown hyena (Hyaena brunnea) scats from the central Karoo, South Africa. J. Zool. 231, 679-683 (1993).

74. Maude, G. The comparative ecology of the brown hyaena (Hyaena brunnea) in Makgadikgadi National Park and a neighbouring community cattle area in Botswana MSc thesis, University of Pretoria, (2005).

75. Harihar, A. \& Pandav, B. Influence of connectivity, wild prey and disturbance on occupancy of tigers in the human-dominated western Terai Arc Landscape. PLoS ONE 7, e40105 (2012).

76. Burnham, K. P. \& Anderson, D. R. Model selection and multimodel inference: a practical information-theoretic approach $2 \mathrm{nd}$ edn. (Springer, Berlin, 2002).

77. Balme, G. A., Hunter, L. T. B. \& Slotow, R. Evaluating methods for counting cryptic carnivores. J. Wildl. Manage. 73, 433-441 (2009).

78. Gopalaswamy, A. M. et al. Program SPACECAP: software for estimating animal density using spatially explicit capture-recapture models. Methods Ecol. Evol. 3, 1067-1072 (2012).

79. Williams, S. T. et al. R code and data for estimating brown hyaena density across South Africa. Available from https://figshare.com/s/ f958e 721d38dff237bab (2020).

\section{Acknowledgements}

Funding was received from the Durham University COFUND research fellowship program, the National Research Foundation (NRF), and Panthera. Opinions expressed and conclusions arrived at, are those of the authors and are not necessarily to be attributed to the NRF. STW received funding from the University of Venda postdoctoral grant. We are grateful to the Limpopo Department of Economic Development, Environment and Tourism (LEDET), Ezemvelo KwaZulu-Natal Wildlife, the numerous reserves, Wildlife ACT, Wildlife and Ecological Investments, and Siyafunda Conservation for their support. This research forms part of Camera CATalogue (www.cameracatalogue.org), a division of Panthera's integrated data management system. We would like to thank the Zooniverse (www.zooniverse.org), their staff, and the 12,500 citizen scientists for their assistance in categorizing camera trap data. Our thanks also extend to Maria Gatta for assistance identifying individual brown hyaenas, Matt Rogan for advice on fitting models, to Professor Murray Efford for his advice on secr, and to Dr Henk Slim for helping to use the Durham University High Performance Computing service to speed up data analysis.

\section{Author contributions}

K.S.W., R.A.H., D.M.P., G.K.H.M., R.T.P., and G.A.B. designed the study. R.T.P., G.K.H.M., G.W.-J., K.S.W., and S.T.W. conducted the fieldwork. K.S.W. and R.J.W. processed the images, and S.T.W., C.J.M., and G.K.H.M. analysed the data. S.T.W. and G.K.H.M. prepared the figures. K.S.W. and S.T.W. led writing the manuscript, with contributions from all authors. 


\section{Competing interests}

The authors declare no competing interests.

\section{Additional information}

Supplementary information is available for this paper at https://doi.org/10.1038/s41598-020-77188-7.

Correspondence and requests for materials should be addressed to S.T.W.

Reprints and permissions information is available at www.nature.com/reprints.

Publisher's note Springer Nature remains neutral with regard to jurisdictional claims in published maps and institutional affiliations.

Open Access This article is licensed under a Creative Commons Attribution 4.0 International License, which permits use, sharing, adaptation, distribution and reproduction in any medium or format, as long as you give appropriate credit to the original author(s) and the source, provide a link to the Creative Commons licence, and indicate if changes were made. The images or other third party material in this article are included in the article's Creative Commons licence, unless indicated otherwise in a credit line to the material. If material is not included in the article's Creative Commons licence and your intended use is not permitted by statutory regulation or exceeds the permitted use, you will need to obtain permission directly from the copyright holder. To view a copy of this licence, visit http://creativecommons.org/licenses/by/4.0/.

(C) The Author(s) 2021 